\section{(6) OPEN ACCESS}

\title{
Individual patient data network meta-analysis of mortality effects of implantable cardiac devices
}

\author{
B Woods, ${ }^{1,2}$ N Hawkins, ${ }^{2,3}$ S Mealing, ${ }^{2}$ A Sutton, ${ }^{4}$ W T Abraham, ${ }^{5}$ J F Beshai, ${ }^{6}$ \\ H Klein, ${ }^{7}$ M Sculpher, ${ }^{1,2}$ C J Plummer, ${ }^{8}$ M R Cowie ${ }^{9}$
}

- Additional material is published online only. To view please visit the journal online (http://dx.doi.org/10.1136/ heartjnl-2015-307634).

For numbered affiliations see end of article.

\section{Correspondence to} Beth Woods, Centre for Health Economics, University of York, Heslington, York Y010 5DD, UK; Beth.woods@york.ac.uk

Received 6 February 2015 Revised 24 May 2015 Accepted 18 June 2015 Published Online First 12 August 2015

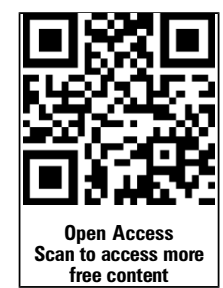

\section{SLinked}

- http://dx.doi.org/10.1136/ heartjnl-2015-308295

CrossMark

To cite: Woods $B$, Hawkins N, Mealing S, et al. Heart 2015;101:

1800-1806.

\section{ABSTRACT}

Objective Implantable cardioverter defibrillators (ICD), cardiac resynchronisation therapy pacemakers (CRT-P) and the combination therapy (CRT-D) have been shown to reduce all-cause mortality compared with medical therapy alone in patients with heart failure and reduced EF. Our aim was to synthesise data from major randomised controlled trials to estimate the comparative mortality effects of these devices and how these vary according to patients' characteristics.

Methods Data from 13 randomised trials (12 638 patients) were provided by medical technology companies. Individual patient data were synthesised using network meta-analysis.

Results Unadjusted analyses found CRT-D to be the most effective treatment (reduction in rate of death vs medical therapy: $42 \%$ (95\% credible interval: 32-50\%), followed by ICD (29\% (20-37\%)) and CRT-P (28\% $(15-40 \%))$. CRT-D reduced mortality compared with CRT-P (19\% (1-33\%)) and ICD (18\% (7-28\%)). QRS duration, left bundle branch block (LBBB) morphology, age and gender were included as predictors of benefit in the final adjusted model. In this model, CRT-D reduced mortality in all subgroups (range: $53 \%(34-66 \%)$ to $28 \%(-1 \%$ to $49 \%))$. Patients with QRS duration $\geq 150 \mathrm{~ms}$, LBBB morphology and female gender benefited more from CRT-P and CRT-D. Men and those $<60$ years benefited more from ICD.

Conclusions These data provide estimates for the mortality benefits of device therapy conditional upon multiple patient characteristics. They can be used to estimate an individual patient's expected relative benefit and thus inform shared decision making. Clinical guidelines should discuss age and gender as predictors of device benefits.

\section{INTRODUCTION}

In addition to optimal medical therapy, implantable cardiac devices have an established role in the treatment of heart failure with reduced EF. International clinical guidelines ${ }^{12}$ make recommendations for implantable cardioverter defibrillators (ICD), cardiac resynchronisation therapy pacemakers (CRT-P) and the combined device, CRT-D, based on the presence of specific patient characteristics, recognising that the clinical benefit associated with these devices varies across subgroups within the broader population of patients with heart failure and reduced EF. These differences arise due to difference in underlying prognosis as well as differences in the relative treatment effects of devices (ie, the HRs comparing alternative interventions).
Estimates of relative treatment effects for patients with different characteristics are, therefore, required to assess the comparative clinical benefit and cost-effectiveness of these devices. With this objective, we pooled individual patient data from all major randomised controlled trials of the devices in a network meta-analysis. This work was developed to inform National Institute for Health and Care Excellence (NICE) guidance for the devices. ${ }^{3}$

Until now, meta-analyses of published randomised trials $^{4-8}$ have reported differences in treatment effects of CRT according to QRS duration and morphology and of ICD according to gender. ${ }^{9}$ In addition, subgroup analyses of individual trials have reported statistically significant variation in all-cause mortality benefit (or composite endpoints, including all-cause mortality) by New York Heart Association (NYHA) class, ${ }^{10}$ QRS duration; ${ }^{11}{ }^{12}$ QRS morphology $^{11}$ and gender. ${ }^{12}$ An individual patient data meta-analysis is the ideal vehicle to explore the effect of these and other patient characteristics on relative treatment effects. This type of analysis avoids reliance on inconsistent individual trial subgroup results or restricting meta-analysis to published subgroup data. A network meta-analysis was necessary as patients with heart failure and reduced EF may benefit from ICD, CRT-D or CRT-P (ie, simple pairwise comparisons do not answer the clinical question of interest). Network meta-analysis (or mixed treatment comparison) allows the synthesis of individual trials that compare different sets of treatments. ${ }^{13}$ For example, the treatment effect for CRT-D versus medical therapy will reflect the direct evidence from COMPANION ${ }^{14-17}$ supplemented by the larger volume of indirect evidence from the CRT-D versus ICD and ICD versus medical therapy trials.

\section{METHODS \\ Systematic review}

A systematic review was conducted to identify randomised controlled trials comparing ICD, CRT-P and CRT-D with each other or with placebo or medical therapy in patients with heart failure and reduced EF (defined as LVEF $\leq 40 \%$ ). All English language full publications from 1990 onwards were considered. Studies were excluded if: patients had experienced recent myocardial infarction or coronary revascularisation ( $\leq 45$ days before enrolment); they compared device variants (eg, different pacing strategies); patients had familial cardiac conditions 
with a high risk of sudden cardiac death or patients had a secondary prevention indication for ICD.

Twenty-two trials were identified, and individual patient-level data from 13 of these were provided by three device manufacturers (Boston Scientific, Medtronic and St. Jude Medical). This represents $95 \%(12,638 / 13,350)$ of patients randomised in the overall network of evidence, see figure 1. 'Optimal' and 'conventional' medical therapy was considered to be equivalent. REsynchonization reVErses Remodeling in Systolic left vEntricular dysfunction (REVERSE) ${ }^{18}$ was considered as four separate designs; Contak-CD ${ }^{19}$ as two separate designs and Miracle $\mathrm{ICD}^{20}$ and Miracle ICD $\mathrm{II}^{21}$ as one trial in keeping with the underlying study designs. The two non-device arms of the Sudden Cardiac Death in Heart Failure Trial (SCD-HeFT) (placebo and amiodarone) ${ }^{10}$ were pooled. Further details of the systematic review are provided in the on-line supplementary appendix.

\section{Network meta-analysis}

A series of network meta-analyses was performed for all-cause mortality. As is standard in network meta-analyses of survival data, ${ }^{22} 23$ we assume that HRs are multiplicative, that is, the HR for CRT-D versus medical therapy can be estimated as the product of the HRs for CRT-D versus ICD and ICD versus medical therapy. This assumption will be violated when differences exist between the trials comparing alternative sets of treatments, and these differences are expected to impact upon the trial HRs. Analyses adjusting for such differences were developed as previous meta-analyses and subgroup analyses support the presence of such differences. ${ }^{4-8} \quad 10-12$

Unadjusted network meta-analyses were performed to establish the efficacy of the devices in the overall randomised populations, to determine the impact of excluding studies for which individual patient data were unavailable and to assess the appropriateness of fixed-effects and random-effects analyses. Adjusted network meta-analyses were performed in order to explore whether patients with different baseline characteristics (age, gender, country (USA vs outside-USA), NYHA class, ischaemic aetiology, LVEF, QRS duration and left bundle branch block (LBBB) morphology) experienced different effects of treatment.
These variables were recorded across the trials and were selected following a review of risk scores, clinical guidelines, trial subgroup analyses and clinical advice. For the adjusted analyses, patients with QRS duration $<120 \mathrm{~ms}$ in CRT trials were excluded as the very low number of deaths (five in total in the CRT arms) made modelling unstable and there is no evidence that CRT is effective in this group. This resulted in the exclusion of 149 patients. In patients with QRS duration $<120 \mathrm{~ms}$, the adjusted analysis only compares ICD with medical therapy. A sensitivity analysis was run restricted to patients with QRS $\geq 120 \mathrm{~ms}$ and NYHA class II-IV as these were considered to be a more homogeneous group.

Data were included from each trial throughout the follow-up period prespecified in the trial protocols. Although longer term follow-up data are available for a number of trials, these were not included because of the high rates of cross-over observed during the additional follow-up periods. ${ }^{24} 25$

\section{Statistical analysis}

The studies for which individual patient data were unavailable reported summary data in binary form (number of deaths and number of participants by arm) rather than as HRs. The binary data were, therefore, combined with HRs obtained from the individual patient data studies using published statistical methods. ${ }^{23}$ These analyses were repeated with and without the data from the studies for which individual patient data were unavailable. Fixed-effects and random-effects analyses were run.

In the analysis adjusting for patient characteristics, individual patient time-to-event data were synthesised across trials using a Cox proportional hazard model stratified by trial. ${ }^{22}{ }^{26}$ All adjusted models were fitted as fixed- effects analyses. In all analyses, the impact of baseline patient characteristics on the efficacy of the devices was assumed to be device specific, reflecting the potentially different mechanisms of action of the devices.

Selection of interaction effects for the adjusted model followed the model selection process described by Collett using a $\mathrm{p}$ value of $0.10 .^{27}$ All results were reviewed for biological plausibility. For the final adjusted model, multiple imputation was used to address missing baseline variables and continuous variables were dichotomised to facilitate presentation.

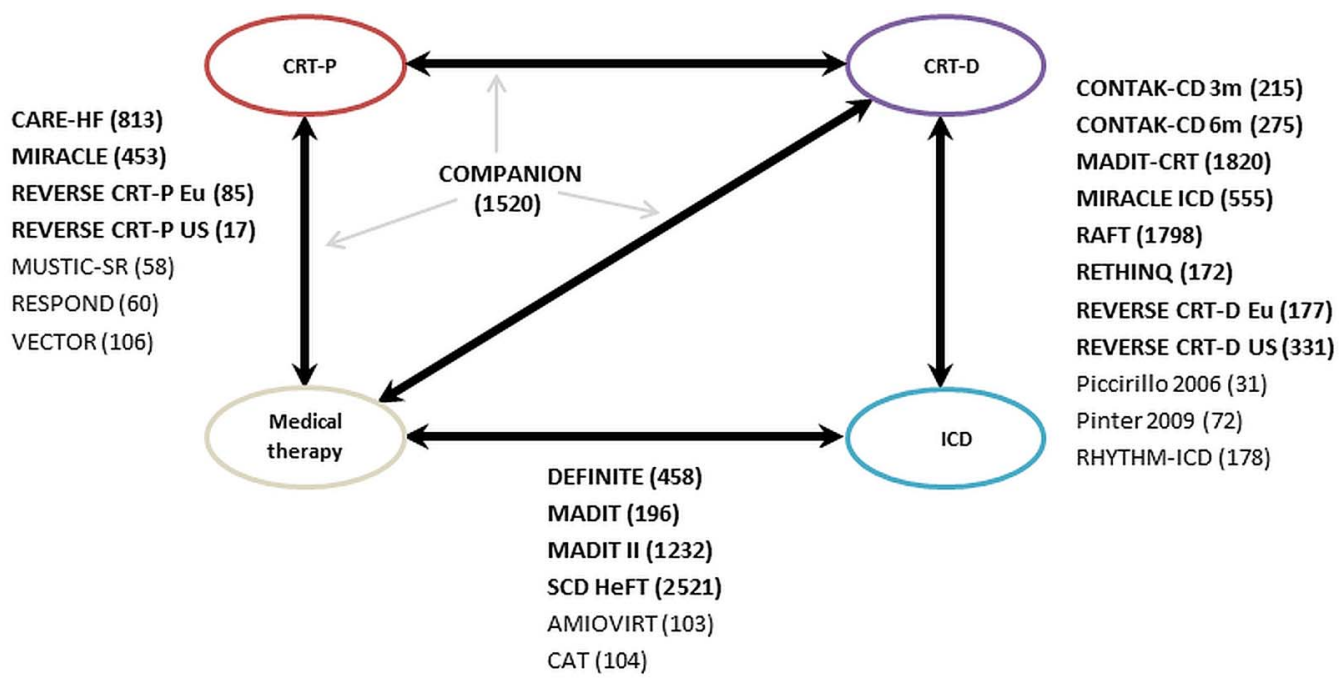

Figure 1 Network of randomised controlled trial evidence. Elipses represent comparators. Arrows represent comparisons of interventions for which trial data were available. Studies for which individual patient data were available are in bold. Patient numbers represent the total number of patients enrolled in each trial informing the comparison of interest. CRT-D, cardiac resynchronisation therapy pacemaker with defibrillation therapy; CRT-P, cardiac resynchronisation therapy pacemakers; ICD, implantable cardioverter defibrillators. 
Further detail regarding the statistical methods is available in the on-line supplementary appendix.

\section{RESULTS}

\section{Individual patient database}

The 12638 patients included in the trial database were followed up for a mean of 2.5 years (range $0-7.5$ years) during which 2422 deaths were observed.

Patient characteristics stratified by trial arm are presented in table 1. There is considerable overlap in the patients randomised to the different treatment options. As expected, patients randomised to CRT-P or CRT-D had longer mean QRS duration and more frequently exhibited LBBB morphology compared with those randomised to medical therapy or ICD. The majority of patients were in NYHA class II or III, with CRT-P trials enrolling more individuals in class III and ICD trials in class II. Only $138(1.1 \%)$ of patients had a LVEF in the $36-40 \%$ range, so the analyses presented are representative of patients with LVEF $\leq 35 \%$.

\section{Unadjusted analysis}

Analysis of all trials (including those for which individual patient data were unavailable) showed CRT-D to be the most effective treatment (HR when compared against medical therapy 0.58 (95\% credible interval: $0.50-0.68)$ ), with CRT-P and ICD showing similar effects on mortality $(0.72(0.60-0.85)$ and 0.71 (0.63-0.80), respectively), compared with medical therapy. Head-to-head device comparisons supported a statistically significant benefit of CRT-D when compared with CRT-P $(0.81(0.67-0.99))$ and ICD (0.82 (0.72-0.93)). Restricting the network to the 13 trials for which individual patient data were available did not alter the results (point estimates and CIs fell within 0.01 of the overall analysis, results not shown). Restriction of the adjusted analysis to trials for which individual patient data were available is therefore unlikely to influence the results.

\section{Adjusted analysis}

Univariate analyses suggested that age, gender, LVEF, QRS duration and LBBB morphology affected mortality benefit, with $\mathrm{p}$ values for the interaction effects ranging from $<0.001$ to 0.043 . These effects were therefore included in a multivariate model. Dropping each set of interaction effects from this model in turn worsened the model significantly for age, gender, LVEF and QRS ( $p$ values $<0.01$ to 0.07 ). Dropping LBBB did not significantly worsen the model fit $(p=0.27)$, but it was, however, retained given its known clinical importance. Adding in covariables that were not significant in the univariate analysis (USA or non-USA-based trial; NYHA class; ischaemic aetiology) did not significantly improve the model fit ( $\mathrm{p}$ values: $0.21-0.71$ ), and they were therefore discarded. The multivariate model and the univariate analyses suggested that lower LVEF (within the range seen in the trials) increased CRT-D efficacy but reduced CRT-P and ICD efficacy. As CRT-D is the combined device, these effects were not deemed clinically plausible. Examination of a dichotomised LVEF variable indicated that the impact of LVEF increased and decreased device effectiveness in biologically improbable patterns over the range of the variable. LVEF was therefore dropped from the final model. QRS duration was split into three categories for the final model ( $<120 \mathrm{~ms}, 120-149 \mathrm{~ms}$ and $\geq 150 \mathrm{~ms}$ ), reflecting commonly accepted clinical thresholds and age was split into two categories ( $<60$ and $\geq 60$ years). The results of univariate network meta-analyses are shown in figure 2 for those variables included in the final multivariate model.

\section{Final model}

The final multivariate model included age, gender, QRS duration and LBBB morphology. Table 2 provides point estimates and CIs from the multivariate model for the treatment effects for each device, by subgroup. This allows estimates of risk and benefit to be made for individual patients with specific QRS duration and morphology, age and gender. The model parameters are reported in the on-line supplementary appendix.

Our model predicts that in all subgroups of patients (LVEF $\leq 35 \%$ and QRS $\geq 120 \mathrm{~ms}$ ), CRT-D is associated with a mortality reduction, which is statistically significant in 15 of 16 subgroups, the exception being men under 60 years, with QRS duration $\geq 120$ to $<150$ ms without LBBB morphology where the CI just spans unity. Estimated relative risk reductions in mortality ranged from $28 \%$ (HR 0.72 (0.51 to 1.01)) in that group to $53 \%$ (HR 0.47 (0.34 to 0.66$)$ ) in women $\geq 60$ years with QRS duration $\geq 150 \mathrm{~ms}$ and LBBB. CRT-D is more effective in those with QRS durations $\geq 150 \mathrm{~ms}$, in those with LBBB and in women, with minimal interaction with age.

CRT-P is more effective at reducing mortality in older patients and in women, in those with QRS duration $\geq 150 \mathrm{~ms}$ and in those with LBBB morphology. In those with the broadest QRS and LBBB, the effect size varied from relative risk

Table 1 Characteristics of patients included in trial database

\begin{tabular}{|c|c|c|c|c|c|}
\hline Intervention & Medical therapy & CRT-D & CRT-P & ICD & Missing (\%) \\
\hline Number of patients & 3477 & 3527 & 1328 & 4306 & 0.0 \\
\hline Age (mean, years) & 61.9 & 65.0 & 65.0 & 63.5 & 0.0 \\
\hline QRS duration (mean, ms) & 130.8 & 156.8 & 162.3 & 140.5 & 1.3 \\
\hline LVEF (mean, \%) & 23.7 & 23.4 & 23.4 & 23.3 & 1.4 \\
\hline Gender (\% female) & 24.0 & 22.5 & 30.1 & 20.7 & 0.0 \\
\hline US (\%) & 81.1 & 61.6 & 62.6 & 68.8 & 0.0 \\
\hline NYHA1 (\%) & 7.7 & 6.0 & 1.1 & 11.4 & 0.1 \\
\hline NYHA2 (\%) & 45.3 & 59.4 & 4.5 & 61.9 & \\
\hline NYHA3 (\%) & 43.5 & 31.1 & 85.3 & 24.9 & \\
\hline NYHA4 (\%) & 3.5 & 3.5 & 9.1 & 1.8 & \\
\hline Ischaemic (\%) & 58.2 & 60.1 & 52.3 & 64.0 & 6.4 \\
\hline LBBB morphology (\%) & 37.5 & 69.4 & 79.7 & 45.6 & 1.8 \\
\hline
\end{tabular}




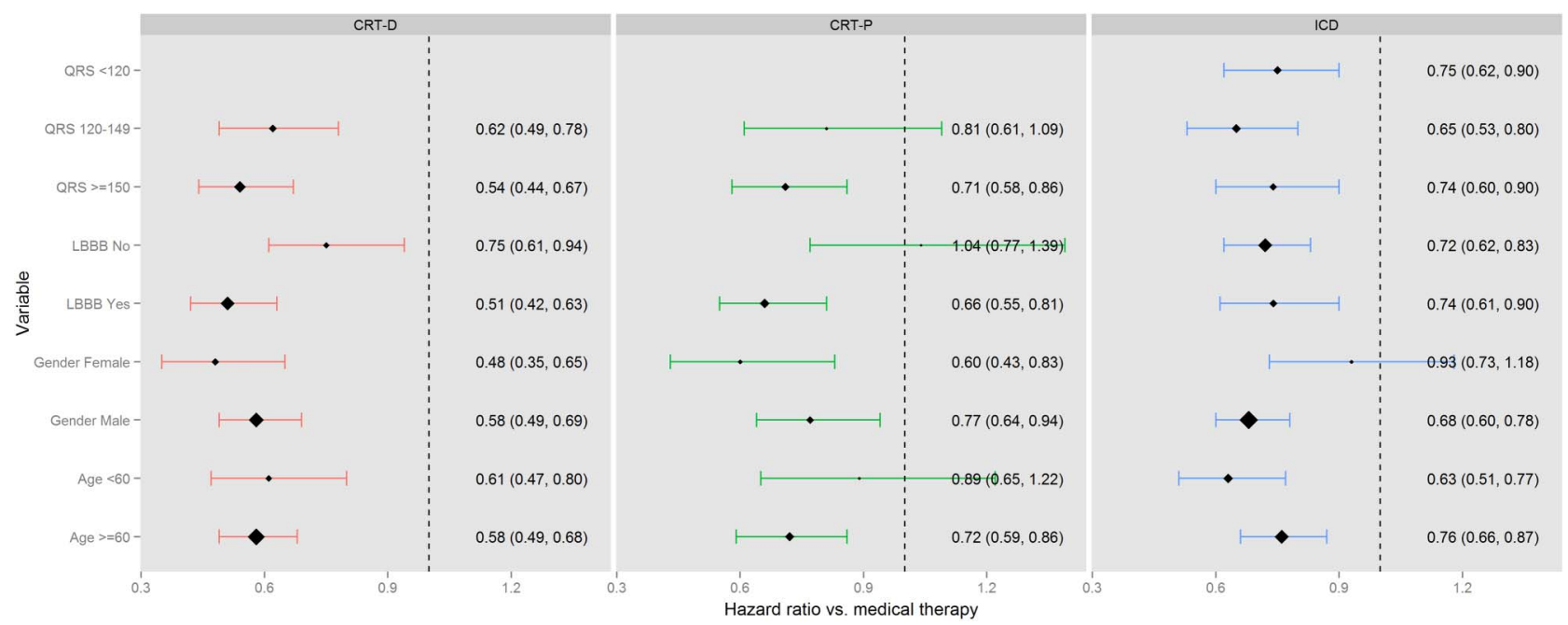

Figure 2 Treatment effect estimates from univariate network meta-analysis model for variables included in final model. The forest plots show the results of the univariate network meta-analysis incorporating individual baseline characteristics as interaction effects. $\mathrm{HRs}$ (mean $(95 \% \mathrm{Cl})$ ) are presented relative to medical therapy with values $<1.0$ indicating reduced all-cause mortality. CRT-D, cardiac resynchronisation therapy pacemaker with defibrillation therapy; CRT-P, cardiac resynchronisation therapy pacemakers; ICD, implantable cardioverter defibrillators; LBBB, left bundle branch block.

reduction of $20 \%$ (HR 0.80 (0.56 to 1.14)) in younger men to $44 \%$ (HR 0.56 (0.40 to 0.79 )) in older women. A substantially lower effect was observed in those with QRS duration 120$149 \mathrm{~ms}$ and no LBBB (varying from no benefit or potential harm (HR 1.07 (0.70 to 1.64$)$ ) in men aged $<60$ years to $25 \%$ relative risk reduction (HR 0.75 (0.46 to 1.21)) in women aged $\geq 60$ years).

In contrast, the mortality benefit of ICD therapy is greater in men than in women, and less apparent in older patients. For all subgroups of men, the effect size was statistically significant with relative risk reductions between $24 \%$ and $48 \%$. For women, the estimated mortality benefit of ICD was smaller and the CIs in 9 of the 10 subgroups spanned unity. The estimated effect sizes were smaller for all subgroups of men and women aged 60 years or more, compared with younger patients.
The sensitivity analysis restricted to patients with QRS $\geq 120$ and NYHA II-IV produced similar results though predicted greater effectiveness of CRT-D and CRT-P in patients $<60$ years and no longer suggested that CRT-P effectiveness depended on age. For full results, see the on-line supplementary appendix.

\section{DISCUSSION}

This individual patient data network meta-analysis incorporated data from all major trials of ICD, CRT-P and CRT-D in patients with heart failure and reduced EF. The data set included 2422 deaths in 12638 patients, representing 95\% of all patients randomised in the clinical trials of these technologies.

Tools developed using individual patient characteristics to estimate treatment benefits are the cornerstone of personalised medicine. Unlike conventional subgroup analyses which present

Table 2 Subgroup-specific treatment effects predicted by multivariate adjusted network meta-analysis

\begin{tabular}{|c|c|c|c|c|c|c|c|c|c|}
\hline \multirow[b]{2}{*}{ Gender } & \multirow[b]{2}{*}{ Age } & \multirow[b]{2}{*}{ QRS } & \multirow[b]{2}{*}{ LBBB } & CRT-D vs MT & CRT-P vs MT & ICD vs MT & CRT-D vs CRT-P & CRT-D vs ICD & ICD vs CRT-P \\
\hline & & & & \multicolumn{6}{|l|}{ HR $(95 \% \mathrm{Cl})$} \\
\hline \multirow[t]{10}{*}{ Female } & \multirow[t]{5}{*}{$<60$} & $<120$ & $\mathrm{~N}$ & & & $0.82(0.60$ to 1.13$)$ & & & \\
\hline & & $\geq 120$ to $<150$ & $\mathrm{~N}$ & 0.62 (0.40 to 0.96$)$ & $0.86(0.50$ to 1.48$)$ & $0.69(0.48$ to 0.99$)$ & $0.72(0.40$ to 1.30$)$ & $0.90(0.58$ to 1.39$)$ & 0.80 (0.46 to 1.39 ) \\
\hline & & $\geq 120$ to $<150$ & Y & $0.55(0.36$ to 0.84$)$ & $0.76(0.46$ to 1.25$)$ & 0.74 (0.51 to 1.07$)$ & $0.72(0.42$ to 1.25$)$ & 0.74 (0.48 to 1.13$)$ & 0.98 (0.58 to 1.64$)$ \\
\hline & & $\geq 150$ & $\mathrm{~N}$ & $0.55(0.35$ to 0.86$)$ & $0.74(0.42$ to 1.28$)$ & $0.77(0.52$ to 1.13$)$ & $0.74(0.41$ to 1.35$)$ & $0.71(0.46$ to 1.12$)$ & 1.04 (0.59 to 1.83$)$ \\
\hline & & $\geq 150$ & Y & $0.48(0.33$ to 0.72$)$ & $0.65(0.42$ to 1.00$)$ & $0.82(0.59$ to 1.15$)$ & $0.75(0.45$ to 1.24$)$ & $0.59(0.40$ to 0.87$)$ & 1.27 (0.79 to 2.04$)$ \\
\hline & \multirow[t]{5}{*}{$\geq 60$} & $<120$ & $\mathrm{~N}$ & & & 1.01 (0.76 to 1.36$)$ & & & \\
\hline & & $\geq 120$ to $<150$ & $\mathrm{~N}$ & $0.60(0.41$ to 0.90$)$ & $0.75(0.46$ to 1.21$)$ & 0.85 (0.62 to 1.17$)$ & 0.81 (0.48 to 1.37$)$ & 0.71 (0.48 to 1.04$)$ & 1.14 (0.70 to 1.87 ) \\
\hline & & $\geq 120$ to $<150$ & Y & $0.53(0.37$ to 0.78$)$ & 0.65 (0.42 to 1.02$)$ & 0.91 (0.66 to 1.27$)$ & 0.82 (0.51 to 1.32$)$ & 0.59 (0.41 to 0.84$)$ & 1.39 (0.89 to 2.20$)$ \\
\hline & & $\geq 150$ & $\mathrm{~N}$ & $0.53(0.35$ to 0.80$)$ & $0.64(0.39$ to 1.03$)$ & 0.94 (0.66 to 1.34$)$ & $0.84(0.50$ to 1.40$)$ & 0.57 (0.38 to 0.84$)$ & 1.48 (0.91 to 2.41$)$ \\
\hline & & $\geq 150$ & Y & $0.47(0.34$ to 0.66$)$ & 0.56 (0.40 to 0.79$)$ & $1.01(0.76$ to 1.35$)$ & $0.84(0.56$ to 1.27$)$ & $0.47(0.34$ to 0.64$)$ & 1.81 (1.24 to 2.64$)$ \\
\hline \multirow[t]{10}{*}{ Male } & \multirow[t]{5}{*}{$<60$} & $<120$ & $\mathrm{~N}$ & & & 0.62 (0.48 to 0.79$)$ & & & \\
\hline & & $\geq 120$ to $<150$ & $\mathrm{~N}$ & 0.72 (0.51 to 1.01$)$ & 1.07 (0.70 to 1.64$)$ & $0.52(0.39$ to 0.69$)$ & $0.67(0.42$ to 1.06$)$ & 1.37 (0.98 to 1.92$)$ & 0.49 (0.31 to 0.76$)$ \\
\hline & & $\geq 120$ to $<150$ & Y & 0.63 (0.44 to 0.91$)$ & 0.94 (0.61 to 1.43$)$ & $0.56(0.40$ to 0.78$)$ & $0.68(0.43$ to 1.07$)$ & $1.13(0.80$ to 1.61$)$ & 0.60 (0.38 to 0.93$)$ \\
\hline & & $\geq 150$ & $\mathrm{~N}$ & 0.63 (0.44 to 0.91$)$ & 0.91 (0.58 to 1.42$)$ & $0.58(0.42$ to 0.80$)$ & $0.69(0.43$ to 1.12$)$ & 1.10 (0.78 to 1.54$)$ & 0.63 (0.40 to 1.00$)$ \\
\hline & & $\geq 150$ & Y & $0.56(0.40$ to 0.77$)$ & 0.80 (0.56 to 1.14$)$ & $0.62(0.46$ to 0.83$)$ & $0.70(0.46$ to 1.06$)$ & $0.90(0.67$ to 1.23$)$ & 0.77 (0.52 to 1.15$)$ \\
\hline & \multirow[t]{5}{*}{$\geq 60$} & $<120$ & $\mathrm{~N}$ & & & 0.76 (0.62 to 0.94$)$ & & & \\
\hline & & $\geq 120$ to $<150$ & $\mathrm{~N}$ & 0.70 (0.53 to 0.92$)$ & $0.92(0.64$ to 1.32$)$ & 0.64 (0.51 to 0.81$)$ & $0.76(0.52$ to 1.10$)$ & $1.09(0.85$ to 1.39$)$ & 0.70 (0.48 to 1.00$)$ \\
\hline & & $\geq 120$ to $<150$ & Y & $0.62(0.46$ to 0.83$)$ & 0.81 (0.57 to 1.16$)$ & $0.69(0.52$ to 0.91$)$ & $0.76(0.53$ to 1.11$)$ & $0.90(0.69$ to 1.16$)$ & 0.85 (0.59 to 1.23$)$ \\
\hline & & $\geq 150$ & $\mathrm{~N}$ & $0.62(0.46$ to 0.83$)$ & $0.79(0.55$ to 1.12$)$ & $0.71(0.54$ to 0.93$)$ & $0.78(0.54$ to 1.13$)$ & $0.87(0.67$ to 1.12$)$ & 0.90 (0.63 to 1.30$)$ \\
\hline & & $\geq 150$ & Y & $0.54(0.43$ to 0.69$)$ & 0.69 (0.55 to 0.87$)$ & 0.76 (0.60 to 0.96$)$ & 0.79 (0.59 to 1.05$)$ & 0.72 (0.59 to 0.87$)$ & 1.10 (0.83 to 1.46$)$ \\
\hline
\end{tabular}

CRT-D, cardiac resynchronisation therapy pacemaker with defibrillation therapy; CRT-P, cardiac resynchronisation therapy pacemakers; ICD, implantable cardioverter defibrillators; LBBB, left bundle branch block; MT, medical therapy. 
results stratified by a single characteristics, our multivariate analysis allows the expected relative effect of alternative devices to be assessed based on an individual patient's QRS duration, LBBB morphology, age and gender by reading off the relevant HR from table 2. These results could be integrated with a prediction model for mortality in untreated patients, to predict life expectancies for alternative devices. This could be included in a webbased decision tool ${ }^{28}$ and integrated into a 'patient decision aid' to facilitate shared decision making and informed consent. ${ }^{29}$

The results for the unadjusted network meta-analysis are consistent with those published previously, ${ }^{30}$ but, in addition, the current analysis shows a statistically significant benefit of CRT-D over both ICD and CRT-P, with the differences driven by evidence from more recently published trials. ${ }^{11} 1218$ Given the heterogeneity within and across the included studies, the unadjusted results may be confounded.

The adjusted analysis suggests that increasing QRS duration and LBBB morphology are associated with greater mortality benefit from CRT. This is consistent with the mechanism of mechanical cardiac resynchronisation in LBBB, and the higher risk of pump failure deaths among patients with longer QRS durations. Analyses of published data have found both variables to improve CRT efficacy in univariate analyses. ${ }^{4} 5$ A recent meta-analysis of individual patient data from 3872 patients included in five CRT (P or D) trials found no association between LBBB morphology and CRT efficacy for all-cause mortality when QRS duration had been controlled for. ${ }^{7}$ This meta-analysis was smaller than that presented here (662 deaths in 3872 patients compared with 2422 deaths in 12638 patients with 1430 deaths observed in CRT trials) and pooled results from CRT-P with CRT-D and ICD with medical therapy.

We also found important effects of age and gender. These effects are likely to be related to the underlying risk of competing causes of death; sudden (presumed arrhythmic) death, pump failure or other causes. Women are less likely to experience sudden cardiac death than men. ${ }^{31}$ Similarly, although the incidence of sudden cardiac death increases with age, the proportion of cardiac deaths that are sudden decreases owing to high numbers of other cardiac causes of death. ${ }^{32} 33$ As CRT delivers most of its benefit through pump function and ICD by treating arrhythmias leading to sudden cardiac death, this may explain the higher efficacy of ICD therapy in younger patients and men, and the higher efficacy of CRT in women. The effects of age and gender observed by pooling these trials were not observed consistently in the individual studies. Nor have they been identified in previous meta-analyses, with one exceptionan analysis of published subgroup data that showed lower efficacy of ICD on all-cause mortality in women. ${ }^{9}$

No evidence was found for interaction effects of devices with NYHA class, aetiology or LVEF. Of course, these variables do predict absolute incremental mortality benefit from therapy as they are known to be predictive of life expectancy in the absence of device intervention. ${ }^{34}$

Our analysis is in line with current clinical guidance (table 3), though suggests that there is no evidence to support different recommendations according to a patients aetiology. It also suggests that age and gender play a significant role in determining the relative benefit of alternative devices. For example, although CRT-D offers benefits over ICD in the overall patient population, in men strong evidence of benefit is only observed for those with the strongest indication for CRT ( $\geq 60$ years, QRS $\geq 150 \mathrm{~ms}, \mathrm{LBBB})$. Gender is mentioned in the CRT guideline as predictive of improved effect but not in guidance for ICD use, and neither guideline mentions age.
Table 3 Summary of relevant international guidance

\begin{tabular}{|c|c|c|c|}
\hline Device & Patient group & Recommendation & Reference \\
\hline \multirow[t]{5}{*}{ CRT-P } & $\begin{array}{l}\text { LVEF } \leq 35 \% \text {, NYHA class II, III, } \\
\text { ambulatory class IV: }\end{array}$ & & 35 \\
\hline & $\mathrm{QRS} \geq 150$ ms with $\mathrm{LBBB}$ & Class I Level A & \\
\hline & QRS $\geq 150$ ms without LBBB & Class Ila Level B & \\
\hline & QRS $\geq 120$ to $<150 \mathrm{~ms}$ with $\mathrm{LBBB}$ & Class I Level B & \\
\hline & $\begin{array}{l}\text { QRS } \geq 120 \text { to }<150 \text { ms without } \\
\text { LBBB }\end{array}$ & Class Ilb Level B & \\
\hline \multirow[t]{3}{*}{ ICD } & LVEF $\leq 35 \%$, NYHA class II-III & & 2 \\
\hline & Ischaemic & Class I Level A & \\
\hline & Non-ischaemic & Class I Level B & \\
\hline \multirow[t]{2}{*}{ CRT-D } & $\begin{array}{l}\text { Patients in whom CRT-P is } \\
\text { indicated and ICD is planned }\end{array}$ & Class I Level A & 35 \\
\hline & $\begin{array}{l}\text { Patients with indicators of better } \\
\text { prognosis and/or ischaemic heart } \\
\text { disease }\end{array}$ & Class Ila Level B & \\
\hline
\end{tabular}

\section{Limitations}

This analysis does not explore the impact of atrial fibrillation or chronic kidney disease on device efficacy. Of the 10 CRT trials in the individual patient database, only one included patients with permanent atrial fibrillation. ${ }^{11}$ Earlier analyses indicated that data on serum creatinine was unavailable for approximately one third of patients. There were, therefore, insufficient data to assess the impact of either of these features on mortality.

Outcomes for the therapies studied are dependent on both device hardware and programming. This analysis reflects the

\section{Key messages}

What is already known on this subject?

- Implantable cardioverter defibrillators (ICD), cardiac resynchronisation therapy pacemakers (CRT-P) and the combination therapy (CRT-D) reduce all-cause mortality compared with medical therapy alone. Similarly, CRT-D reduces all-cause mortality compared with ICD. Limited data exist to compare CRT-D with CRT-P. Evidence of how the mortality benefit of these implantable devices varies with patient characteristics is largely limited to individual trial subgroup analyses.

\section{What might this study add?}

- This individual patient data network meta-analysis found that patients with QRS duration $\geq 150 \mathrm{~ms}$, left bundle branch block morphology and female gender benefited more from CRT-P and CRT-D, and those $<60$ years and of male gender benefited more from ICD.

How might this impact on clinical practice?

- The analysis allows the survival benefit of each device to be estimated for specific patient groups.

- This information can be used directly in assessments of net clinical benefit and cost-effectiveness. This evidence has been used in this way at the National Institute for Health and Care Excellence (NICE) in their recent guidance update. 
efficacy of the devices and leads available at the time and as programmed in the clinical trials. With the benefit of current technology, we would expect greater efficacy of ICD and CRT in clinical practice. Evidence regarding the impact of these factors on outcomes should be taken in to account when considering alternative interventions.

The results should not be extrapolated to patients with characteristics absent or under-represented within the data. Namely, to the effect of CRT in patients with NYHA class I or QRS duration $\leq 120 \mathrm{~ms}$, to CRT-P in patients with NYHA class II or to any patients with LVEF $>35 \%$.

Given the different impacts of CRT and ICD therapy on pump failure and sudden cardiac death, ${ }^{17}{ }^{36}$ it would have been interesting to analyse the impact of the devices on each cause of death. This was not pursued, as there were concerns about the reliability and consistency in the assignment of mode of death.

Value for money is another important consideration at the healthcare system level. The analysis reported here alongside further analysis of this database to estimate hospitalisation rates and quality of life has been used to inform such a costeffectiveness analysis. ${ }^{3}$ This will be the subject of a separate publication.

\section{Author affiliations} \\ ${ }^{1}$ Centre for Health Economics, University of York, York, UK \\ ${ }^{2}$ Department of Health Economics, ICON Clinical Research, Oxford, UK \\ ${ }^{3}$ Department of Health Services Research and Policy, London School of Hygiene and \\ Tropical Medicine, London, UK \\ ${ }^{4}$ Department of Health Sciences, University of Leicester, Leicester, UK \\ ${ }^{5}$ Ohio State University Medical Centre, Ohio, USA \\ ${ }^{6}$ Mayo Clinic, Phoenix, Arizona, USA \\ ${ }^{7}$ University of Rochester, New York, USA \\ ${ }^{8}$ Freeman Hospital, Newcastle upon Tyne, UK \\ ${ }^{9}$ Imperial College London (Royal Brompton Hospital), London, UK
}

Acknowledgements Jeff Cerkvenik (Medtronic), Jennifer Duggan (St. Jude Medical), Elena Ivanova (St. Jude Medical), Andi Schaechter (Northwestern University) and Haris Subacius (Northwestern University) provided database management and statistical support in assembling trial data held by their organisations and in responding to queries relating to the delivered data. Leticia Barcena (Oxford Outcomes Ltd.) conducted the systematic review. Ben Brown (Medtronic), Mark Chapman (Medtronic), Sheri Dodd (Medtronic), Steve Fearn (St. Jude Medical), Michael Ferguson (Boston Scientific), Mark McIntyre (Boston Scientific), Parashar Patel (Boston Scientific), Rodamni Peppa (Boston Scientific), Sine Rose (St. Jude Medical), Dan Schaber (Medtronic), Antje Smala (Biotronik), Adrian Squires (Sorin) and Nathalie Verin (Boston Scientific) provided logistical support and scientific input during the course of the project. Judith Mellis (Association of British Healthcare Industries) provided logistical support throughout the project.

Contributors $\mathrm{BW}$ conducted the analysis under the supervision of $\mathrm{NH}$ and with assistance from SM. BW, NH, SM, AS, MS, CJP and MRC contributed to the design of the work and interpretation of data. WA, JB and HK contributed to acquisition of data. BW, MRC and CJP drafted the manuscript. All authors contributed to revising the manuscipt and approved it for final submission. Contributors: Jeff Cerkvenik (Medtronic), Jennifer Duggan (St. Jude Medical), Elena Ivanova (St. Jude Medical), Andi Schaechter (Northwestern University) and Haris Subacius (Northwestern University) provided database management and statistical support in assembling trial data held by their organisations and in responding to queries relating to the delivered data. Leticia Barcena (Oxford Outcomes Ltd) conducted the systematic review. Ben Brown (Medtronic), Mark Chapman (Medtronic), Sheri Dodd (Medtronic), Steve Fearn (St. Jude Medical), Michael Ferguson (Boston Scientific), Mark McIntyre (Boston Scientific), Parashar Patel (Boston Scientific), Rodamni Peppa (Boston Scientific), Sine Rose (St. Jude Medical), Dan Schaber (Medtronic), Antje Smala (Biotronik), Adrian Squires (Sorin) and Nathalie Verin (Boston Scientific) provided logistical support and scientific input during the course of the project. Judith Mellis (Association of British Healthcare Industries) provided logistical support throughout the project.

Funding This work was supported by Biotronik, Boston Scientific, Medtronic, Sorin and St. Jude Medical. MRC's salary is funded by the National Institute for Health Research Cardiovascular Biomedical Research Unit at the Royal Brompton Hospital, London. CJP's salary is funded by Newcastle upon Tyne Hospitals NHS Foundation Trust.
Competing interests BW, SM and NH were employees of Oxford Outcomes Ltd during the period of this work. MS is a consultant to Oxford Outcomes Ltd and received payment for his involvement in this work. AS was a paid consultant to Oxford Outcomes Ltd for this work. MRC provides consultancy advice to Medtronic, Boston Scientific and St. Jude Medical and has had research grants from Medtronic. CJP has received research funding and travel grants to attend scientific meetings and has provided consultancy advice to Medtronic, Boston Scientific and St. Jude Medical. HK has provided consultancy advice and has received research funding from Boston Scientific. William Abraham has received consulting fees from St. Jude Medical and Biotronik.

Provenance and peer review Not commissioned; externally peer reviewed.

Open Access This is an Open Access article distributed in accordance with the Creative Commons Attribution Non Commercial (CC BY-NC 4.0) license, which permits others to distribute, remix, adapt, build upon this work non-commercially, and license their derivative works on different terms, provided the original work is properly cited and the use is non-commercial. See: http://creativecommons.org/ licenses/by-nc/4.0/

\section{REFERENCES}

1 Yancy CW, Jessup M, Bozkurt B, et al. 2013 ACCF/AHA guideline for the management of heart failure: a report of the American College of Cardiology Foundation/American Heart Association Task Force on Practice Guidelines. J Am Coll Cardiol 2013:62:e147-239.

2 McMurray JJ, Adamopoulos S, Anker SD, et al. ESC guidelines for the diagnosis and treatment of acute and chronic heart failure 2012: The Task Force for the Diagnosis and Treatment of Acute and Chronic Heart Failure 2012 of the European Society of Cardiology. Developed in collaboration with the Heart Failure Association (HFA) of the ESC. Eur Heart I 2012:33:1787-847.

3 National Institute for Health and Care Excellence. Implantable cardioverter defibrillators and cardiac resynchronisation therapy for arrhythmias and heart failure (review of TA95 and TA120). NICE technology appraisal guidance 314. NICE, 2014:1-71

4 Sipahi I, Carrigan TP, Rowland DY, et al. Impact of QRS duration on clinical event reduction with cardiac resynchronization therapy: meta-analysis of randomized controlled trials. Arch Intern Med 2011;171:1454-62.

5 Sipahi I, Chou JC, Hyden M, et al. Effect of QRS morphology on clinical event reduction with cardiac resynchronization therapy: meta-analysis of randomized controlled trials. Am Heart J 2012;163:260-7.

6 Stavrakis S, Lazzara R, Thadani U. The benefit of cardiac resynchronization therapy and QRS duration: a meta-analysis. J Cardiovasc Electrophysio/ 2012;23:163-8.

7 Cleland JG, Abraham WT, Linde C, et al. An individual patient meta-analysis of five randomized trials assessing the effects of cardiac resynchronization therapy on morbidity and mortality in patients with symptomatic heart failure. Eur Heart J 2013;34:3547-56

8 Wells G, Parkash R, Healey JS, et al. Cardiac resynchronization therapy: a meta-analysis of randomized controlled trials. CMAJ 2011;183:421-9.

9 Santangeli P, Pelargonio G, Dello Russo A, et al. Gender differences in clinical outcome and primary prevention defibrillator benefit in patients with severe left ventricular dysfunction: a systematic review and meta-analysis. Heart Rhythm 2010:7:876-82

10 Bardy GH, Lee KL, Mark DB, et al. Amiodarone or an implantable cardioverter-defibrillator for congestive heart failure. [Erratum appears in $N \mathrm{Engl} / \mathrm{J}$ Med 2005;352:2146]. N Engl J Med 2005;352:225-37.

11 Tang AS, Wells GA, Talajic M, et al. Cardiac-resynchronization therapy for mild-to-moderate heart failure. N Engl J Med 2010;363:2385-95.

12 Moss AJ, Hall WJ, Cannom DS, et al. Cardiac-resynchronization therapy for the prevention of heart-failure events. N Engl J Med2009;361:1329-38.

13 Caldwell DM, Ades AE, Higgins JP. Simultaneous comparison of multiple treatments: combining direct and indirect evidence. BMJ 2005;331:897-900.

14 Anand IS, Carson P, Galle E, et al. Cardiac resynchronization therapy reduces the risk of hospitalizations in patients with advanced heart failure: results from the Comparison of Medical Therapy, Pacing and Defibrillation in Heart Failure (COMPANION) trial. Circulation 2009;119:969-77.

15 Bristow MR, Saxon LA, Boehmer J, et al. Cardiac-resynchronization therapy with or without an implantable defibrillator in advanced chronic heart failure. $N$ Engl J Med 2004;350:2140-50.

16 Bristow MR, Feldman AM, Saxon LA. Heart failure management using implantable devices for ventricular resynchronization: Comparison of Medical Therapy, Pacing, and Defibrillation in Chronic Heart Failure (COMPANION) trial. J Card Fail 2000;6:276-85.

17 Carson P, Anand I, O'Connor C, et al. Mode of death in advanced heart failure: the Comparison of Medical, Pacing, and Defibrillation Therapies in Heart Failure (COMPANION) trial.[Erratum appears in J Am Coll Cardiol.2008 Jun 3; 51(22): 2197 Note: Ghali, Jalil [corrected to Ghali, Jalal]]. J Am Coll Cardiol 2005;46:2329-34. 
18 Linde C, Abraham WT, Gold MR, et al. Randomized trial of cardiac resynchronization in mildly symptomatic heart failure patients and in asymptomatic patients with left ventricular dysfunction and previous heart failure symptoms. J Am Coll Cardiol 2008;52:1834-43.

19 Higgins SL, Hummel JD, Niazi IK, et al. Cardiac resynchronization therapy for the treatment of heart failure in patients with intraventricular conduction delay and malignant ventricular tachyarrhythmias. J Am Coll Cardiol 2003;42:1454-9.

20 Young JB, Abraham WT, Smith AL, et al. Combined cardiac resynchronization and implantable cardioversion defibrillation in advanced chronic heart failure: the MIRACLE ICD Trial. JAMA 2003;289:2685-94.

21 Abraham WT, Young JB, Leon AR, et al. Effects of cardiac resynchronization on disease progression in patients with left ventricular systolic dysfunction, an indication for an implantable cardioverter-defibrillator, and mildly symptomatic chronic heart failure. Circulation 2004;110:2864-8.

22 Tudur-Smith C, Marson AG, Chadwick DW, et al. Multiple treatment comparisons in epilepsy monotherapy trials. Trials 2007;8:34.

23 Woods BS, Hawkins N, Scott DA. Network meta-analysis on the log-hazard scale, combining count and hazard ratio statistics accounting for multi-arm trials: a tutorial. BMC Med Res Methodol 2010;10:54.

24 Cleland JG, Freemantle N, Erdmann E, et al. Long-term mortality with cardiac resynchronization therapy in the Cardiac Resynchronization-Heart Failure (CARE-HF) trial. Eur J Heart Fail 2012;14:628-34.

25 Goldenberg I, Gillespie J, Moss AJ, et al. Long-term benefit of primary prevention with an implantable cardioverter-defibrillator: an extended 8-year follow-up study of the Multicenter Automatic Defibrillator Implantation Trial II. Circulation 2010:122:1265-71.

26 Tudur-Smith C, Williamson R, Marson AG. Investigating heterogeneity in an individual patient data meta-analysis of time to event outcomes. Stat Med 2005;24:1307-19.
27 Collett D. Modelling survival data in medical research. 2nd edn. Florida: Chapman and Hall CRC, 2003.

28 Spertus JA, Bach R, Bethea C, et al. Improving the process of informed consent for percutaneous coronary intervention: Patient Outcomes from the Patient Risk Information Services Manager (ePRISM) study. Am Heart J 2015;169: 234-241.e1.

29 Kramer DB, Brock DW, Tedrow UB. Informed consent in cardiac resynchronization therapy what should be said? Circ Cardiovasc Qual Outcomes 2011:4:573-7.

30 Lam SK, Owen A. Combined resynchronisation and implantable defibrillator therapy in left ventricular dysfunction: Bayesian network meta-analysis of randomised controlled trials. BMJ 2007;335:925.

31 Saxon LA, Bristow MR, Boehmer J, et al. Predictors of sudden cardiac death and appropriate shock in the Comparison of Medical Therapy, Pacing, and Defibrillation in Heart Failure (COMPANION) Trial. Circulation 2006;114:2766-72.

32 Abildstrom SZ, Rask-Madsen C, Ottesen MM, et al. Impact of age and sex on sudden cardiovascular death following myocardial infarction. Heart 2002;88:573-8.

33 Tung $\mathrm{P}$, Albert CM. Causes and prevention of sudden cardiac death in the elderly. Nat Rev Cardiol 2013;10:135-42.

34 Levy WC, Mozaffarian D, Linker DT, et al. The Seattle Heart Failure Model: prediction of survival in heart failure. Circulation 2006;113:1424-33.

35 Brignole M, Auricchio A, Baron-Esquivias G, et al. 2013 ESC Guidelines on cardiac pacing and cardiac resynchronization therapy: the Task Force on cardiac pacing and resynchronization therapy of the European Society of Cardiology (ESC). Developed in collaboration with the European Heart Rhythm Association (EHRA). Eur Heart J 2013;34:2281-329.

36 Packer DL, Prutkin JM, Hellkamp AS, et al. Impact of implantable cardioverterdefibrillator, amiodarone, and placebo on the mode of death in stable patients with heart failure: analysis from the sudden cardiac death in heart failure trial. [Erratum appears in Circulation. 2010 Feb 16;121(6):e39]. Circulation 2009;120:2170-6. 